\title{
IDENTIFYING ADOPTERS AND NON-ADOPTERS OF BROADBAND AMONGST SILVER SURFERS: USING BHPS
}

Choudrie, Jyoti; Grey, Susan; Haslam, Colin and Tsitsianis, Nicholas. University of Hertfordshire, Business School, Hatfield, Herts. AL10 9AB, UK.

e-mail: j.choudrie@ herts.ac.uk* ${ }^{1}$;.grey@ $@$ herts.ac.uk; c.j.haslam@herts.ac.uk; n.tsitsianis@ @erts.ac.uk

\begin{abstract}
The aim of this paper is to identify the adopters and non-adopters of Broadband within the silver surfer group. This was achieved using the British Household Panel Survey, a large scale survey used to collect data from UK households. The data was analysed using statistical tools, such as, SPSS v. 15. The conclusions drawn are that Broadband will be adopted in nuclear households (no presence of elderly) with silver surfers who have children aged between 12 and 18 without ignoring the role played by a relatively level of education. This research offers contributions for academics by providing an objective viewpoint of the factors leading to Broadband adoption within silver surfers, a group of immense, current interest. For industry, this research offers an intensive identification of socio-economic factors that are considered important when marketing a product or service within the market.
\end{abstract}

Keywords: Digital Divide, E-Government, Silver Surfers, Adoption, Socio-Economic Factors, Broadband

\section{INTRODUCTION}

Recognising the potential that Information and Communications Technologies (ICTs) offer for competitiveness and the effectiveness of communities, Governments across the globe are striving to provide online products and services ${ }^{2}$ to all user groups (Mofleh et al, 2009). This has led to a 'supply and demand', 'push and pull' strategy in economies, and efforts from and partnerships to be formed between many government (public) and private sector organisations and citizens. However, despite all efforts, certain groups of society-disadvantaged groups such as the disabled, older people and people from poorer backgrounds are not using online products and services, which has led to a 'digital divide' (Dwivedi and

\footnotetext{
${ }^{*}$ Contact person e-mail: j.choudrie@ herts.ac.uk

${ }^{2}$ There are various definitions of e-government, but for the purposes of this research, the definition used is: E-government is more commonly known as the the provision of online products and services (Chircu, 2008)
} 
Williams, 2008). As with any novel issue, initially there are various definitions and the same applies to the digital divide. Our definition of the digital divide follows Norris (2001). Norris conceptualized the digital divide as operating on three levels and it is the second and third levels that formed the basis of this research:

- The global divide refers to the divergence of internet access between industrialized and developing countries;

- The social divide concerns the gap between information rich and information poor in each nation;

- The democratic divide signifies the difference between those who do, and those who do not, use the panoply of digital resources to engage, mobilise, and participate in public life.

Presently, new technologies, such as Information and Communication Technologies (ICTs) ${ }^{3}$ are viewed as critical tools for the future prosperity and growth of economies and there is a drive from both the public and private sectors to have ICTs adopted and used in daily lives. From United Kingdom (UK) official published figures, it was discovered that although ownership of ICT related artefacts, the internet and mobile phones, was increasing amongst all age groups, it was not so pronounced in the older groups. “Just over four in ten over-65s (41\%) had a PC or laptop in Q1, compared to the UK average of $72 \%$, while $37 \%$ had internet access at home against an all-adult average of 67\%. The difference was even more apparent with Broadband, where those aged over 65 were less than half as likely to have a home connection (27\% compared to the UK average of 58\%). For all of these services the figures became even more pronounced when looking at the over-75 age group. Almost all of those aged 75 or older had a landline at home ... Over a quarter (28\%) had a PC or laptop but only $22 \%$ had home internet access and this fell to 15\% with a Broadband connection" (Ofcom, 2008, p.11). In UK, elderly social isolation is an issue of concern $(\mathrm{BBC}, 2008)$ and has led to agencies, research institutes and policy makers to seek ways of combating it. A solution that some local authorities have considered pertinent to address this issue is the use of ICTs (Leicestershire County Council, 2009). Policymakers, even at the level of the

\footnotetext{
${ }^{3}$ Examples of ICTs include Broadband (the offering of a faster internet service), personal digital assistants, such as, blackberries and mobile telephones
} 
Prime Minister of the UK, have recognized that having no broadband, a situation applicable to the elderly population equates to social deprivation (BBC, 2009). This has led to policymakers seeking ways of providing broadband, which include partnerships in the public and private sectors (BBC, 2009).

While the above offers a UK perspective, such trends are also emerging in Europe where internet penetration is lowest amongst the elderly, lowly educated or low income people, confirming that socioeconomic factors are important when considering aspects of the digital divide (Kaplan, 2005).

According to UK Office of National Statistics (2008), people aged over 60 in the UK outnumbered children for the first time. However, in the current environment where there are dramatic transformations occurring in medicine, health care and the environment, this is not an uncommon situation in many countries across the globe. It was noted that such situations are not disappearing and may eventually become common place. Presently, as mentioned above, there are numerous e-government efforts being undertaken by global governments. Since e-government services are primarily web based services, older users could face cognitive, visual or physical problems when trying to access information using this medium (Becker, 2005). Further, adults over the age of 60 usually experience a decrease in motor coordination, hence, making it increasing difficult for them to use web sites to retrieve information (Becker, 2005). For example, older users may find it difficult to coordinate on screen mouse activity or scroll down a Web page (Becker, 2005).

\subsection{EXAMINING E-GOVERNMENT IN THE UK}

To ensure that all citizens in a country have access to technology, to achieve digital inclusion and to illustrate a clear vision to all, Governments have formed and implemented policies and undertaken programmes to encourage awareness and usage amongst citizens. An example is the launch of the eEurope Action Plan in 2002 that places digital inclusion at the top of the EU policy agenda. Alakeson et al (2003) in their report for the EU on Social Responsibility and the Information Society made a number 
of recommendations for government, for business and for further research. With regard to the latter, they identified a need for greater understanding of digital inclusion, and in particular, identified the factors that enable people to move up and down the digital ladder. They acknowledge that there is already evidence of a payoff to commitment to digital inclusion. For example: Household internet penetration in the EU has increased dramatically from 18.3\% in March 2000 to 34.3\% in December 2001. But, this positive headline masks various discrepancies in uptake. Household internet penetration in the Netherlands is over $65 \%$ and rising, in contrast to Greece where it has fallen last year to below 10\%.......Similarly, internet penetration among other traditionally disadvantaged groups - the disabled, the elderly, and the poorly educated-falls far below the EU average. (Alakeson et al, 2003, p.4).

An example of policies used to overcome the digital divide further away from the UK and Europe, which has led to increasing success and obtained a leading position for a country in terms of Broadband use, is the case of South Korea: "The South Korean government used a variety of promotion policies designed to boost Internet use amongst the population. These measures included IT literacy and Internet literacy programmes targeted at particular populations such as housewives, the elderly, military personnel, farmers and socially excluded sectors such as low-income families, the disabled and even prisoners. The government set up the "Ten Million People Internet Education" project in June 2000 to provide Internet education to 10 million people through a range of programmes. (Lee et al., 2003, p.17).”

In UK, the digital divide is considered an important issue, but has not been undertaken on a government and policy level to the same extent as South Korea. Instead, initiatives at a more local level have occurred and led to a narrowing of the digital divide gap. A key principle of the UK e-government initiative is to socially include all citizens in the modernisation process. This includes members of society who are poor, disabled, and unemployed, ethnic minority groups, young, old and the educationally and culturally deprived (Hicken, 2004; Crown, 2004). Nonetheless, to encourage e-services adoption amongst citizens, the UK Government has pioneered projects using UK online centres, Learn Direct, and Wired up 
Communities, as well as valuable local initiatives (Choudrie and Dwivedi, 2006). Local initiatives include, People's Network, which was a scheme offered by the local governments using lottery provided funds, within public libraries. This scheme offered access to the internet and computers to the citizens. Additionally, the Government has created Directgov (www.direct.gov.uk), an online portal that allows citizens to access services offered by Government from a centralised location. As Selwyn and Craven (2008) found: "ICT has fallen significantly down the agenda of more recent strategies, largely as a result of the success of regional campaigns to promote access to Broadband services".

The UK Government has been supporting e-government and narrowing the digital divide in the following ways.

- In 2007 it was found that at least $£ 424$ m of mainly UK government money was currently invested in projects that promote digital inclusion or that could be leveraged to do so (Digital Inclusion Team, 2007).

- A Social Exclusion Unit being established by the current (Labour) government in 1997 to examine and develop policy dealing with social exclusion. One of the Policy Action Teams-PAT 15 was focused on looking at ICTs and social exclusion with the goal "to develop a strategy to increase the availability and take-up of information and communications technology (ICT) for people living in poor neighbourhoods"4. The team commissioned reports on a number of issues, including, women, race, disability, White Males with manual backgrounds, and current ICT use in deprived areas. A final report with findings and recommendations was presented in February 2000.

- Recently (2008) a new ministerial position to combat the digital inclusion issue has been established. The Secretary of State for Wales, Mr. Paul Murphy attained the position in January 2008 and is attempting to overcome the issue. This move has also obtained the formation of a cross-sectional cabinet committee and a Digital Action Plan to overcome the digital inclusion gap.

\footnotetext{
${ }^{4}$ http://www.cabinet-office.gov.uk/seu/2000/Compendium/15.htm
} 
However, such efforts are still not being considered enough. Despite all efforts, provisions for the elderly are still low. Recent research has found: "Absolutely no progress has been made in getting older people online and the spotlight is now on Government and the industry to get switched on," Head of Policy, Help the Aged (BBC, 2008, page 1).

In the above context, the aim of this study is: To identify the adopters and non-adopters of Broadband within the the silver surfer ${ }^{5}$ group, using the socio-economic factors available within a large scale survey.

This research is considered beneficial and timely as Governments are striving hard to provide all citizens with online access- a 'universal' Broadband, which is succeeding, but to a limited extent (BBC, 2008). This has led to the issue of the digital divide to become a subject of immense importance, and one that is increasingly researched. This research adds to the discussions regarding silver surfers and the potential digital divide. The academic contribution of this research is the employment of a particular evaluative technique that is being employed to determine the technical and non-technical factors that will lead to a narrowing or elimination of the digital divide.

For policy makers, the implications of this research are that policy makers working hard at ensuring Broadband provision for all can understand and determine the initiatives being achieved at grassroots levels. Therefore, they can utilize such results as test beds for future programmes and have a preunderstanding of the efforts that their support would achieve. Such research can also support management level executives in public and private sector organizations that are considering the continuing challenge of digital exclusion and what can be done to eliminate it. By identifying groups that

\footnotetext{
${ }^{5}$ An adult, generally 50 years of age or older, who frequently surfs the $\underline{\text { Web }}$ and spends time online ("silver" refers to the color of their hair). The phrase silver surfer is commonly heard in the U.K., but applies to midlife adults (generally those in their $40 \mathrm{~s}$, 50s and 60s), and seniors (age 70 and over) everywhere (netlingo, 2008)
} 
are excluded from broadband accessibility, managers can implement appropriate strategies to ensure that all the citizens within a country are offered broadband. For ISPs, this research is vital as it draws attention to factors that may not have been clearly articulated. An example: this research draws attention to the fact that although silver surfers state that they have Broadband, they are not making use of it; therefore, there is a gap for the providers of Broadband to fill.

In the following sub-sections a discussion of the other topics of this research, the digital divide and egovernment in the UK, which is the main context of this research is offered. Section 2 then reviews some of the theoretical aspects of evaluation, followed by section 3 which details the approach applied to this research. The findings and analysis resulting from the research approach are presented in Sections 4 and 5. This is then followed by conclusions in section 6 .

\section{THEORETICAL UNDERPINNINGS}

The topics of interest in this research are the silver surfers and identifying the adopters and non-adopters within this group. However, there are also some theoretical underpinnings regarding this research that is described below.

\subsection{BROADBAND, THE DIGITAL DIVIDE, ADOPTERS AND NON-ADOPTERS AND ECONOMIC THEORIES}

From the time "Broadband" was introduced to the world, there has been immense interest in it. This is due to Broadband being viewed to be an innovation for the technology area as it offers better access and quality of internet content. However, before proceeding further, a term frequented within this paper is 'broadband' and a short explanation of it is provided. The umbrella term of broadband technology embraces a variety of high-speed access technologies including ADSL (Asymmetric Digital Subscriber Line), cable modems, satellite, and Wi-Fi (Wireless Fixed) Networks. The term broadband has no established definition. It varies across countries (Firth and Kelly, 2001) and evolves over time as 
underlying transmission and routing technologies continuously advance: yesterday's broadband is today's 'narrowband'. Given the variations in defining 'broadband', the Broadband Advisory Group, Australia's expert body on broadband issues reporting to the Federal Government, defines broadband as 'the ability of a single access line or wireless or satellite link, connected to a telecommunications network, to provide support for fast, always-on access to digital content, applications and a range of services, some or all of which can occur simultaneously' (BAG, 2003, p.2). The definition is technology neutral, that is, less to do with technical speed, and focuses on functionality, that is, more to do with what a user can do with broadband. BAG also suggests that while broadband currently means always-on data services of 200 Kbps or more, a third generation of services with $10 \mathrm{Mbps}$ needs to be considered for future transitions to next generation broadband services. Given the broadband services available in Australia, this proposed research uses a working definition of broadband as 'always-on data services of $200 \mathrm{Kbps}$ or more', following the BAG's suggestion.

In the current global environment, areas of immense research interest that are still associated with broadband are the issues regarding the adoption and usage of it (Analysys Mason, 2008; Crabtree, 2003). Early studies on Broadband socio-demographics suggest that socio-demographic attributes such as, income, educational attainment and the current employment status of the residential (household) consumers have a positive correlation to internet access rates; however the age of a consumer has a negative correlation (Anderson et al, 2002). Other findings from previous studies represent the sociodemographic trend of innovators, which may or may not represent the early and late adopters (Dwivedi and Irani, 2008). Furthermore, Stanton (2004) recommends that an inquiry that addresses the access question and the demographics suggesting the usefulness of observations of any changes in the likelihood of socioeconomic groups is pertinent.

When considering the adoption of Broadband, the demand (consumer) aspect of market forces analysis is important. Previous studies have examined factors of Broadband with discussions initially focusing upon 
macro factors that drive the success or slow uptake of Broadband deployment (Lee et al, 2003). Choudrie and Dwivedi (2005) began to examine micro factors by studying adopters and non-adopters; in this case, within a UK local authority and found that as with other similar home technologies such as computers, the demographic characteristics of consumers such as age, gender and social class have an imperative role in explaining the adoption of Broadband in households. However, they also learnt that demographic characteristics such as, education fail to distinguish the adopters from non-adopters. To determine whether similar socioeconomic factors trends will emerge, Dwivedi and Williams (2008) undertook a study of socio-economic factors on UK e-government initiatives and its impact on the digital divide. They found that age, education, and Broadband access at home significantly influence a citizens' adoption of the Government Gateway, whilst gender was found to be non-significant, which is a contradiction to the previous study.

This research progresses a step further to previous studies to explore the 'silver surfer consumer's' demographic characteristics in terms of adopters and non-adopters of Broadband in UK. Given the concern that silver surfers are not adopting Broadband up to the government and market's expectations, it was felt that such research would be beneficial; since it would identify how the silver surfers, a group that is viewed to be critical for the future and needs to be encouraged and motivated to adopt Broadband Internet in the home.

An additional focus of this research is that of consumers, and at this point the differentiating factor between the terms of 'consumers' and 'users' is provided. According to Rice (1997) 'consumers' are those who pay for services and goods, whilst 'users' are individuals who are affected by or who affect the product or services. In other words, users are those who utilise a product and service but do not pay for it (Rice, 1997). For example, a child can be categorised as a user since he/she uses Broadband for online gaming and for completing his/her homework; however, the child does not pay for the service. In contrast, parents are consumers as they pay for the internet service. For the purpose of this paper, consumers are further classified as 'adopters' and 'non adopters'. The term 'adopters' has been used for 
respondents with Broadband subscriptions in the home; whilst 'Non-adopters' are defined as respondents who may or may not be using dialup and do not possess Broadband at home.

\subsection{THE THEORY OF EXPECTED UTILITY}

From the previous section, findings have indicated that theories from various other disciplines are essential for forming an understanding of Broadband adoption. For instance, in previous research, the discipline of Marketing assisted our research by providing an understanding of the differences between 'consumers' and 'users' of Broadband. A discipline that can also assist in providing an understanding of consumer choices is Economics. Madden and Simpson (1996), using Australian Census data, applied a binary probit regression model to estimate households that are less likely to subscribe and examine whether there exists a systematic link between subscription interest and commonly accepted measures of social disadvantage. They undertook this on stated-preference subscription data obtained from a national survey of one thousand households. Their results found that there exists the potential for an information poor class to develop. Earlier, Bodnar et al. (1988), using Canadian telephone subscription data, report that the probability of having a telephone is higher in urban areas than in rural areas.

In their research, Madden and Simpson (1996) examined households and Broadband, but in a different context, which led to us adopting a strategy similar to them. We assumed that households have a preference between 'adopting' Broadband and, 'having no' Broadband in order to maximise expected utility. The difference in the expected utility from Broadband and the expected utility from nonBroadband, $Y^{*}$, is a latent or unobserved variable, ranging from $-\infty$ to $+\infty$. This latent variable is related or being a function of observable personal and household characteristics $(X)$. That is: $\mathbf{Y i}^{*}=\mathbf{X}_{\mathbf{i}} \mathbf{i} \mathbf{i} \mathbf{k}+\mathbf{\varepsilon i}[\mathbf{1}]$. Where $i$ indicates the observation (or the household) and $\varepsilon i$ is a random error (proxy for the unknown or non-captured variables). Relevant independent variables $(X i)$ are those that may affect the household's $i$ need for Broadband versus non-Broadband, indicating greater (less) utility (or satisfaction) with 
Broadband, as $X i$ increase, when $\beta k$ is positive (negative) ${ }^{6}$. The link between the observed binary $Y$ (Broadband or non-Broadband) and the latent $Y^{*}$ is made with a simple measurement equation:

$$
Y i=\left\{\begin{array}{l}
1 \text { if } \mathrm{Yi}^{*}>0 \\
0 \text { if } \mathrm{Yi}^{*} \leq 0
\end{array}\right.
$$

Cases with positive values of $Y^{*}$ are observed as $Y=1$, whereas cases with negative or zero values of $Y^{*}$ are observed as $Y=0$. In this instance, respondents face a dichotomous question about whether a household has adopted Broadband. We let $Y=1$ if the respondent lives in a household that has adopted Broadband and $Y=0$ if the respondent lives in a household that has not adopted it. Not all the respondents or the households that have adopted Broadband $(Y=1)$ are recorded with the same certainty. One household might be close to terminating its contract; whereas, another could be firm in its decision to continue with its contract.

In both cases, we observed $Y=1$. The idea of a latent $Y^{*}$ is that an underlying propensity to adopt Broadband generates the observed state. Again, although propensity is not directly observed,, at some point a change in $Y^{*}$ results in a change in our observations; namely, whether the household has adopted Broadband. Hence, for a set of independent variables allocated the value of $X i$, we see that: $\operatorname{Pr}(\mathbf{Y}=\mathbf{1} \mid \boldsymbol{X i})$ $=\operatorname{Pr}\left(\mathbf{Y}^{*}>\mathbf{0} \mid \boldsymbol{X i}\right) \quad$ [2]. Hence, a binary Probit is used to relate the probability of adopting Broadband to a set of demographic variables. As stated above, a dichotomous $(0,1)$ variable is used to classify households as households already adopted Broadband (1) or not (0). The model is of the form (with parameters $\beta$ and explanatory variables $X$ being defined above $)^{7}: \mathbf{Y i}=\mathbf{F}\left(\boldsymbol{\alpha}+\boldsymbol{\beta} 1 \mathbf{X}_{\mathbf{i} 1}+\boldsymbol{\beta}_{2} \mathbf{X}_{\mathbf{i} 2}+\ldots+\right.$ $\left.\boldsymbol{\beta}_{\mathbf{k}} \mathbf{X}_{\mathbf{i k}}\right)=\mathbf{F}\left(\mathbf{X}_{\mathbf{i}} \mathbf{i}^{\mathbf{\beta}} \mathbf{k}\right)[3]$. Where $F($.$) is the cumulative distribution function.$

\footnotetext{
${ }^{6}$ Equation [1] is identical to those for a linear regression model except that the dependent variable is unobserved.

${ }^{7}$ As stated above, if we assume that the error term, $\varepsilon$, is normally distributed with variance, $\sigma^{2}(\varepsilon)=1$ and Mean $(\varepsilon)=0$ then this leads to the binary probit model. The estimates produced by probit are distributed asymptotically normally.
} 
Although signs of the parameter $\beta$ indicate the direction of the relationship between the explanatory variables and the probability of adopting Broadband, the coefficient itself is not directly interpretable (see McElvey and Zavoina, 1975). Hence, next to the parameter estimates we report the transformed coefficients, the so-called Marginal or Partial Effects. The latter being the change in the probability caused by a unit change in the independent variable, or, from moving from 0 to 1 for a dummy variable.

\section{RESEARCH METHOD}

Previous research completed by Choudrie and Dwivedi (2005) found that a reliable sample frame (for instance, the electoral register) representing the UK population, is beneficial and necessary for a survey research method. For this purpose, the British Household Panel Survey (BHPS) was employed. The BHPS is a nationally representative panel data set of individuals and households residing in the UK, thereby offering an intensive, non-biased and objective outcome. All the adults in the sampled households are interviewed once a year. The original selected sample pursued a stratified random sampling procedure, and interviews were initially held with the sample in 1991, with annual surveys undertaken thereafter. In 1991, the survey comprised some 5,500 households and 10,000 individuals. However, new households are formed every year with household members leaving their "old" households and then being added to the sample. There are also changes in the sample numbers due to death and sample attrition. The panel is also periodically refreshed with new samples. Hence, as time elapses, the sample size increases progressively. Since 2000, more than 15,000 adults have been interviewed on an annual basis. Therefore, the sample remains broadly representative of the population of the UK, using the undertaken changes of the 1990s and the first half of 2000 .

When analyzing the survey, the emphasis was on the years or waves (terminology used in BHPS) that incorporate Broadband-related questions. It was found that BHPS incorporated Broadband focused questions only in 2006. The BHPS core questionnaire responses are obtained from elicited individual information regarding personal characteristics, current employment status, household composition, 
employment status, income, educational level, health and region. These are variables that have been studied widely and viewed as important within the marketing discipline (Rice, 1997). Therefore, a study of the demographics of broadband 'silver surfer' consumers may assist in identifying diverse segments' specific needs and assist with market segmentation. The sample used for this research consisted of adults (both males and females) and the data consisted only of completed replies. Having removed cases with missing or inconsistent data for any of the relevant variables, we obtained 7,765 replies, of which the silver surfers comprised 1,987 (25.50\%). The collated data was analysed using SPSS version 15 as well as Stata version 9. This allowed the calculation of the response frequencies, merging of files, asymptotic tstatistics and coefficients to analyse the variables determined by this research. It is recognised that previous Information Systems (IS) researchers have used other analysis tools to analyse and present research findings using response frequencies, percentage (Webster, 1998; Venkatesh \& Brown, 2001).

\section{FINDINGS OF THIS RESEARCH}

When obtaining the findings, men and women aged 18 and over in Wave 16 (2006) and only those who provided completed responses to specific questions during the interviews were considered. A Broadband related question appeared for the first time only in the Wave 16 (year 2006) in the form: "Do you have a Broadband connection from your home computer?" At this point, respondents replied in the form of a "Yes" or "No". $\underline{\text { Note: }}$ The questions in this questionnaire only determine whether the household has adopted Broadband. There is no further information on Broadband usage, the intensity of the usage, whether the respondents have access to Broadband outside of their homes, or what members of the households are using Broadband on regular basis. Hence, the respondent to an extent "represents" the household and on the basis of this relationship we were able to match some personal and household characteristics. 
FIGURE 1: Broadband Adoption by Age (\%)

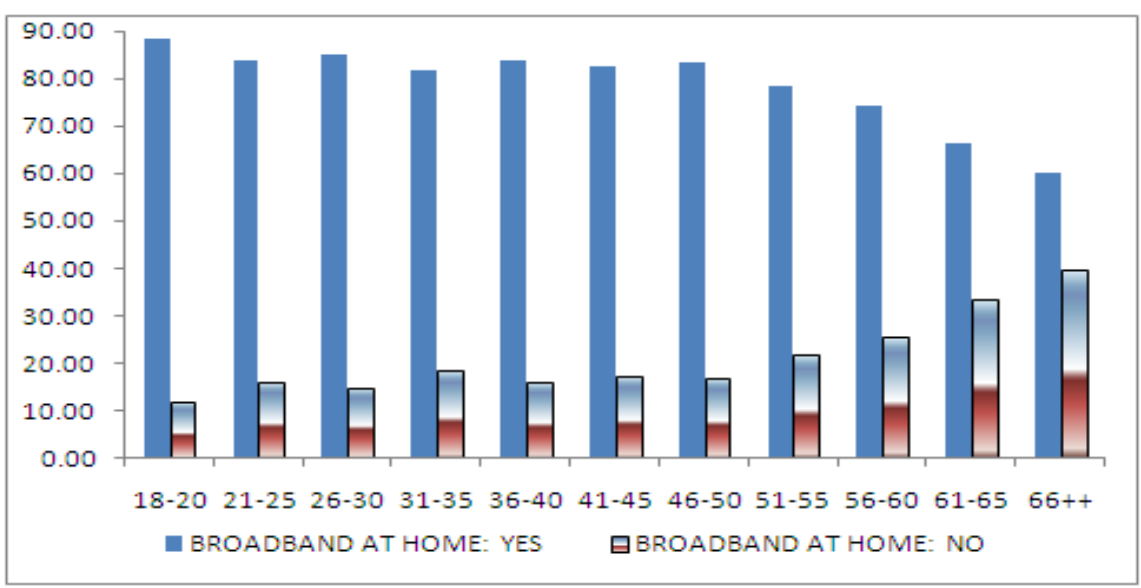

Figure 1 illustrates that in total, $18.50 \%$ of the respondents did not have access to Broadband from the home; whereas, $81.50 \%$ did. Broadband adoption appears stronger for relatively younger respondents and declines, yet not dramatically with respondents' ages. The adoption rates remain fairly constant, but the 51-55 age-band marks the turning point. The representation changes further for households where there are respondents aged between 61 and 65 years old. Table 1 illustrates households with three, four and five occupants (usually one couple with children and no elderly) exhibits high likelihood of Broadband adoption whereas single households, households with no children and relatively large households (more than seven occupants) tend to suppress the likelihood of adopting Broadband at home. This segment of the population contains a large proportion of elderly respondents (households containing pensioners) which is in line with Madden and Simpson's (1996) and Ironmonger and Lloyd-Smith (1992). 
TABLE 1: Broadband and Household Size and Children

\begin{tabular}{|c|c|c|c|c|c|c|c|}
\hline & \multicolumn{3}{|c|}{ Broadband at Home } & & \multicolumn{3}{|c|}{ Broadband at Home } \\
\hline & No $(\%)$ & Yes $(\%)$ & Row Total & & No $(\%)$ & Yes $(\%)$ & Row Total \\
\hline Household Size & & & & No of Children & & & \\
\hline 1 & 28.04 & 71.96 & 453 & $\mathbf{0}$ & 21.04 & 78.96 & 4,230 \\
\hline 2 & 23.65 & 76.35 & 2,051 & 1 & 16.90 & 83.10 & 1,580 \\
\hline 3 & 16.01 & 83.99 & 1,768 & 2 & 13.55 & 86.45 & 1,454 \\
\hline 4 & 15.99 & 84.01 & 2,267 & 3 & 14.65 & 85.35 & 389 \\
\hline 5 & 13.49 & 86.51 & 875 & $4++$ & 26.79 & 73.21 & 112 \\
\hline 6 & 15.85 & 84.15 & 246 & & & & \\
\hline $7++$ & 24.76 & 75.24 & 105 & & & & \\
\hline Observations & & 7,765 & & & & 7,765 & \\
\hline
\end{tabular}

Note: $\chi^{2}$ tests and simple correlation coefficients verify the relationship observed in Table 1. Available from authors upon request

Switching to cross-tabulations, the sample as a whole was examined and it was found that Broadband adoption and education do not seem to follow any distinctive pattern. There is only a slight propensity for households having a member with high educational qualifications to adopt Broadband. However, the patterns were more interesting when the sample was disaggregated by age (see Table 2). Households containing silver surfers and with relatively high education exhibited higher propensities of adopting Broadband, compared to households with silver surfers aged 50 and above, but with relatively lower educational achievements. However, Broadband adoption rates do not vary in households with respondents below 50 years old. Previous research [see, for example, Rogers (1995) Venkatesh et al (2000)] found that highly qualified individuals are more likely to adopt new technologies. Our representative sample found that age appears to have an important role. 
TABLE 2: Broadband and Education

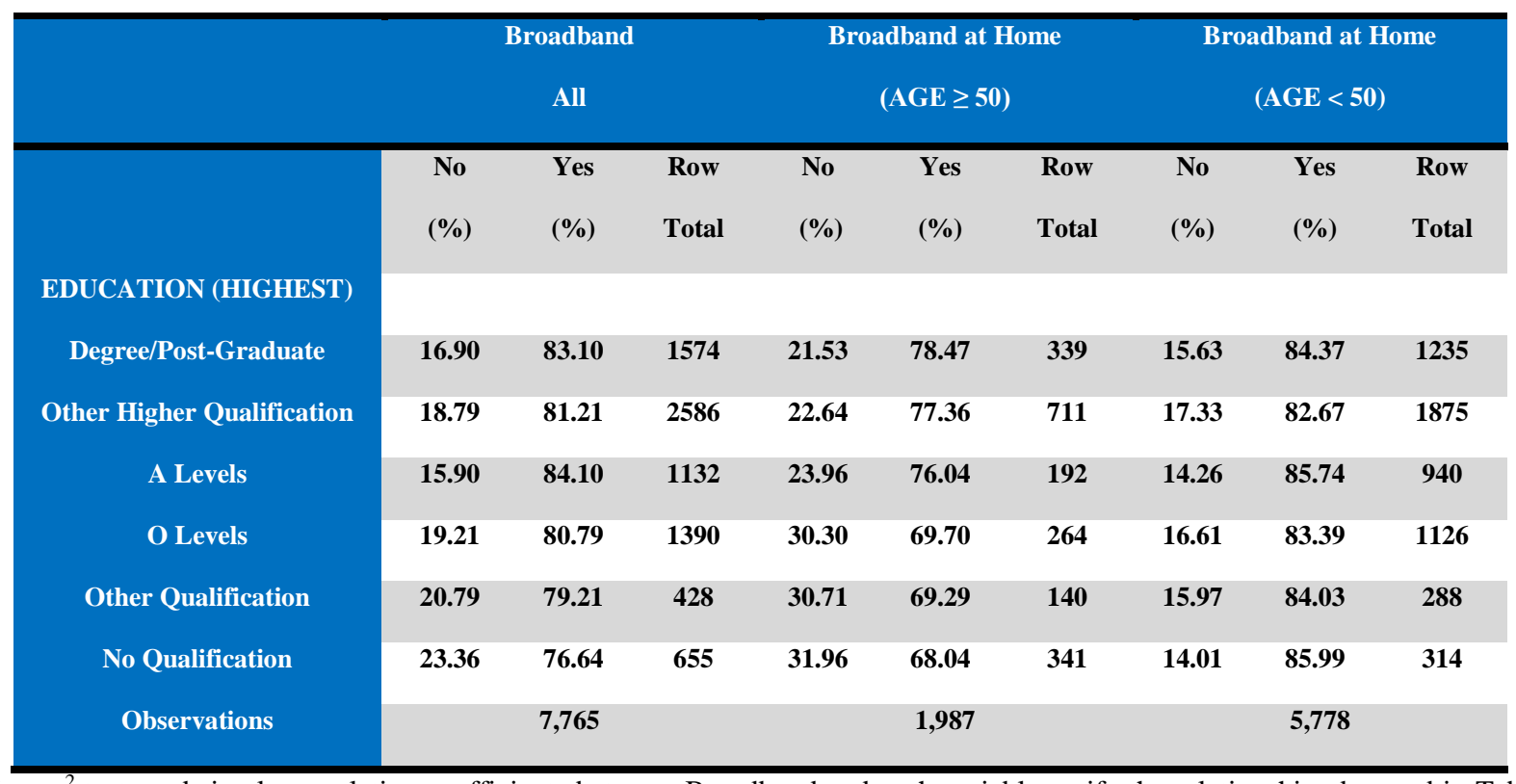

Note: $\chi^{2}$ tests and simple correlation coefficients between Broadband and each variable verify the relationship observed in Table

2. Available from authors upon request

Further cross-tabulations between Broadband adoption, age and labour force status (see Table 3) established that there is a distinctive difference between households in which a respondent is a retiree and households in which a respondent is an active member of the labour force, unemployed or out-of-labour force (maternity leave, long-term sick, family care and government training). Further decomposition by age (the last six columns) unveils significant variations in households with silver surfer respondents ${ }^{8}$

\footnotetext{
${ }^{8}$ The centenary percentage in Table 3 should be treated with caution as in our sample we have only 3 retirees aged below 50 .
} 
TABLE 3: Broadband and Labour Force Status

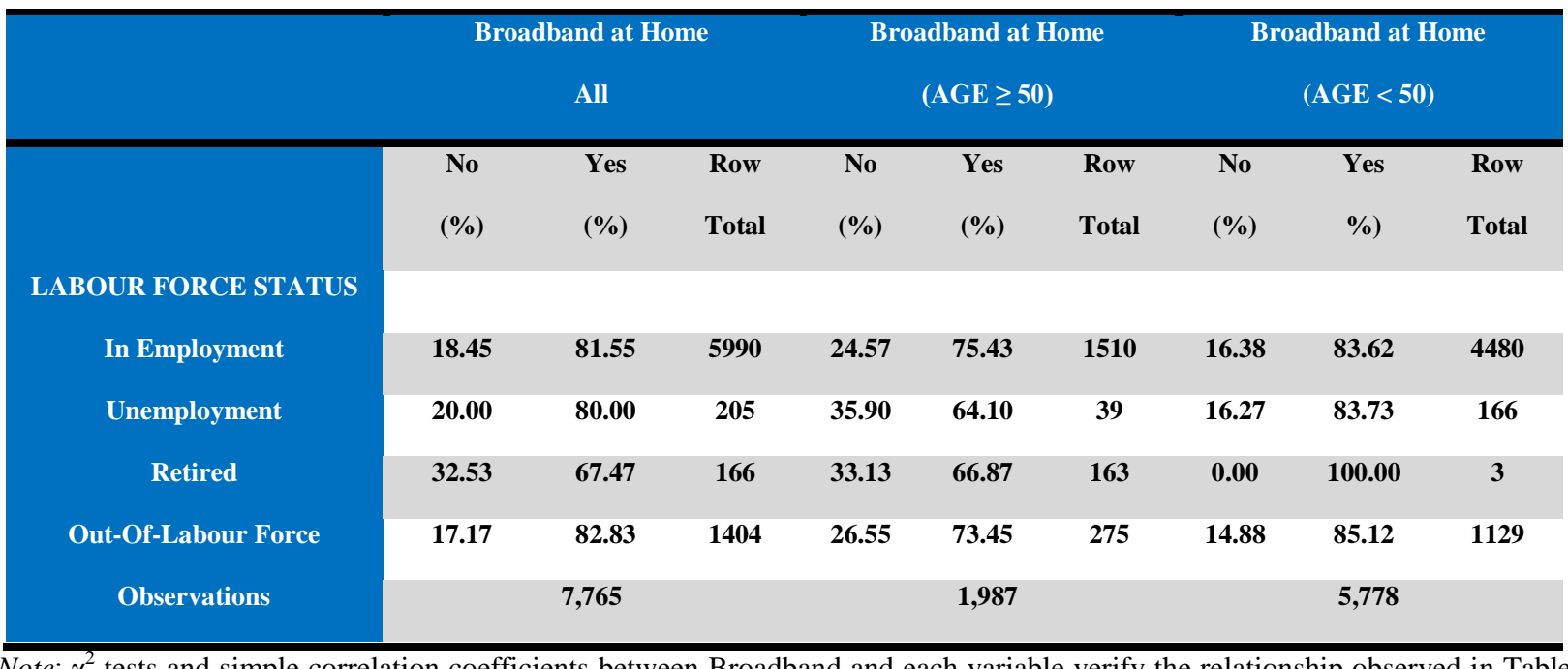

$\underline{\text { Note }}: \chi^{2}$ tests and simple correlation coefficients between Broadband and each variable verify the relationship observed in Table

3. Available from authors upon request

This survey was also beneficial as it allowed the measurement of both labour and non-labour income (see

Table 4). The latter is positively associated with Broadband adoption rates, although they remain relatively high irrespective of the household income band, which suggests that the relationship is rather "weak". However, the relationship between Broadband and household income becomes more pronounced for households with silver surfer respondents, than households with respondents aged below 50 . 
TABLE 4: Broadband and Household Income

\begin{tabular}{|c|c|c|c|c|c|c|c|c|c|}
\hline \multirow[b]{2}{*}{ HOUSEHOLD INCOME (£) } & \multicolumn{3}{|c|}{$\begin{array}{c}\text { Broadband } \\
\text { All }\end{array}$} & \multicolumn{3}{|c|}{$\begin{array}{l}\text { Broadband at Home } \\
\qquad(A G E \geq 50)\end{array}$} & \multicolumn{3}{|c|}{$\begin{array}{l}\text { Broadband at Home } \\
\qquad(\mathrm{AGE}<50)\end{array}$} \\
\hline & $\begin{array}{l}\text { No } \\
(\%)\end{array}$ & $\begin{array}{l}\text { Yes } \\
(\%)\end{array}$ & $\begin{array}{l}\text { Row } \\
\text { Total }\end{array}$ & No $(\%)$ & $\begin{array}{l}\text { Yes } \\
(\%)\end{array}$ & $\begin{array}{l}\text { Row } \\
\text { Total }\end{array}$ & No $(\%)$ & $\begin{array}{l}\text { Yes } \\
(\%)\end{array}$ & $\begin{array}{l}\text { Row } \\
\text { Total }\end{array}$ \\
\hline Less than 10,000 & 22.90 & 77.10 & 262 & 44.59 & 55.41 & 74 & 14.36 & 85.64 & 188 \\
\hline $10,000-20,000$ & 21.01 & 78.99 & 871 & 30.29 & 69.71 & 241 & 17.46 & 82.54 & 630 \\
\hline $20,000-30,000$ & 20.10 & 79.90 & 1453 & 31.41 & 68.59 & 382 & 16.06 & 83.94 & 1071 \\
\hline $30,000-40,000$ & 18.20 & 81.80 & 1648 & 24.80 & 75.20 & 375 & 16.26 & 83.74 & 1273 \\
\hline $40,000-50,000$ & 19.73 & 80.27 & 1262 & 22.74 & 77.26 & 321 & 18.70 & 81.30 & 941 \\
\hline $50,000-60,000$ & 16.70 & 83.30 & 928 & 19.07 & 80.93 & 236 & 15.90 & 84.10 & 692 \\
\hline $60,000-70,000$ & 14.45 & 85.55 & 519 & 21.71 & 78.29 & 129 & 12.05 & 87.95 & 390 \\
\hline More than 70,000 & 15.35 & 84.65 & 821 & 20.52 & 79.48 & 229 & 13.34 & 86.66 & 592 \\
\hline Observations & & $7,7,765$ & & & 1,987 & & & $\overline{\mathbf{5 , 7 7 8}}$ & \\
\hline
\end{tabular}

$\underline{\text { Note }}: \chi^{2}$ tests and simple correlation coefficients between Broadband and each variable verify the relationship observed in Table

4. Available from authors upon request

\section{EMPIRICAL ANALYSIS: MULTIVARIATE RESULTS}

Table 5 presents the probability of a household adopting Broadband given the set of independent variables. Columns 1, 4 and 7 illustrate the coefficients reported by the probit model, whereas columns 2 , 5, and 8 their corresponding $t$-statistics in absolute values. Columns 3, 6 and 9 report the marginal effects $^{9}$. The parameter estimates are illustrated in Table $5^{10}$.

The results explain that broadband adoption appears to be stronger for households in which the respondents are young (recall that our age measurements start at the age of 18, see Figure 1), verifying the results reported by Madden and Simpson (1996). Specification 2 and 3 display a non-linear (or convex) relationship between age and Broadband adoption as the linear term is negative and the quadratic is

\footnotetext{
${ }^{9}$ As it is stated in Section 2.2, the marginal effects measure the partial impact of the corresponding variable on the likelihood of household adoption of Broadband, all other factors constant. The $t$-statistics indicate whether a particular parameter estimate is statistically different from zero, that is, the variable has no impact on Broadband adoption by households.

${ }^{10}$ All the estimations were performed in Stata v.9
} 
positive. However, the quadratic terms dominate the linear ones which effectively imply that broadband adoption declines with respondent age. ${ }^{11}$ Nevertheless, this relationship should be interpreted with caution as it fails to attain to any conventional levels of significance.

The size of the household and more specifically, the number of children appears to exercise a significant impact on Broadband adoption, ceteris paribus. If the family has children aged between 12 and 15 then it is likely to adopt Broadband under all specifications. Additionally, in households with silver surfers, dependents of the ages 12-15 and 16-18 years old, there is an increase in the likelihood of broadband adoption by $5.4 \%$ and $9.4 \%$ respectively, which is similar to the findings obtained by Venkatesh et al (2000). Consistent with preliminary findings, extended households that accommodate pensioners tend to significantly suppress the probability of adopting Broadband especially under Specifications 1 and 3.

It is interesting to note that formal education, per se, has selected economic or statistical impact on the probability of adopting Broadband. The coefficients are generally statistically insignificant with the exception of households containing respondent/s older than 50 years old. In such a household, high educational qualifications are statistically significant, with 'Other Higher Qualifications' exercising the most notable influence on broadband adoption likelihood (8.1\%), followed by A Levels (6.9\%) and Higher Degrees $(6.6 \%)$. This result coincides with the findings of the preliminary analysis above (see Table 2).

Unlike education, the labour market status of a respondent does not appear to have any significant impact on the household probability of adopting Broadband. Specification 2 reports some sizable coefficients, but they fail to reach any conventional level of significance, with all other factors held constant. On the contrary, wealth variables, such as income and house ownership, seem to have contradicting effects on Broadband adoption, with everything else held constant. The positive and economic or statistical association between income and household Broadband adoption remains highly significant irrespective of

\footnotetext{
${ }^{11}$ The turning points for Specification 2 are 88 years old and for Specification 3, 75years old respectively.
} 
the Specification ${ }^{12}$. Nevertheless, the marginal effects are relatively small (1.4\% the most notable one) verifying Table 4 and to a certain degree, Madden and Simpson's (1996) findings. On the other hand, house ownership significantly contains the probability of Broadband adoption. It turns out that those living in rented accommodation have a higher probability of adopting Broadband, ceteris paribus.

Regional decomposition reveals that in general all the households (apart from those located in Wales) are positively associated with the likelihood of adopting Broadband with households located in the NorthWest leading the race (7.9\%). However, only North-Western households, with silver surfers, seem to exercise a significant impact $(11.4 \%)$ on Broadband adoption; whereas the Welsh households tend to suppress the probability of adopting Broadband.

Finally, the predicted probability of adopting Broadband ranges between $75 \%$ and $84 \%$. The households in which the respondent is more than 50 years old are the least likely ones to use Broadband facilities than the corresponding households in which the respondent is less than 50 years. Nevertheless, the probabilities are quite high.

\section{CONCLUSIONS AND FUTURE DIRECTIONS}

In this research study, a unique contribution is offered by applying a nationally representative panel data set (BHPS) of individuals and households residing in the UK. The preliminary analysis and the applied model describe broadband adoption in terms of socioeconomic characteristics. Three different models were fitted and the results suggest that certain characteristics are strong predictors of Broadband adoption. Previous studies, such as Choudrie and Dwivedi (2005) did not consider the silver surfers and used a smaller sample population and found that age, gender and class do have an impact, but in the instance of Choudrie and Dwivedi's (2005) study, education was not a significant factor of consideration. Also, the

\footnotetext{
12 This finding points to the fact that the households appear to be liquidity constrained as higher levels of household income accelerate the Broadband adoption rates and vice versa.
} 
previous studies focused on particular vicinities, which offer a subjective view; whereas this research offers an unbiased and objective viewpoint by employing a large, national and representative data set.

From this research we identified that Broadband will be adopted in nuclear households (no presence of elderly) with silver surfers who have children aged between 12 and 18 without ignoring the role played by a relatively level of education. It also has to be noted that if Broadband and education are considered without any emphasis on age, then education appears to be an insignificant factor of consideration; thereby, confirming Choudrie and Dwivedi's (2005) study.

When considering adopters in terms of the labour force, it can be learnt that households with silver surfers and either in employment or out-of-labour force have a higher probability of adopting Broadband, than households including silver surfers, but either unemployed or retired. This research progressed to offer a unique contribution by examining whether wealth variables, such as income and house ownership, have contradicting effects on Broadband adoption. By doing so, it was learnt that households are to an extent liquidity constrained as higher levels of household income accelerate the Broadband adoption rates and vice versa. However, the impact of the latter is not as sizeable as other variables.

When considering the locations of silver surfers in UK, it was found that silver surfers in North-Western (e.g. Liverpool) households exhibited the highest probability (i.e. 11.4\%) of adopting Broadband; whereas the Welsh households tend to suppress the probability of adopting Broadband. Note: The government is actively promoting internet access using initiatives such as Citizens Online.

We do acknowledge at this point that although this an intensive piece of research, there are limitations to it. Whilst this research has been pertinent in providing an objective overview of Broadband adopters it will be useful to collect in-depth and rich data by conducting interviews that examine variables such as broadband usage of respondents in terms of frequency, or type. This will provide a clearer and complete picture of Broadband adoption amongst the silver surfers and will certainly be helpful in identifying 
critical segments for marketing purposes. It may be useful to examine the moderation affects of demographic variables such as gender, education, income, and social classes amongst the silver surfers on the role of attitudinal, normative and perceived behavioural control factors. Venkatesh and Brown (2001) also called upon researchers to adopt a similar approach. Due to a lack of time and resources this was not possible to include in this study, however such impacts will be examined in future research.

Acknowledgements: The authors would like to express their gratitude to the ECIS review committee and reviewers of this journal for their valuable feedback.

\section{REFERENCES}

Analysys Mason (2008). Models for efficient and effective Public sector interventions in next-generation Broadband $\begin{array}{lll}\text { access } & \text { networks. } & \text { Available }\end{array}$ www.Broadbanduk.org/component/option,com_docman/task,doc_view/gid,1008/Itemid,63/. Viewed on $14 / 11 / 08$.

Anderson, B., C, Gale, M.L.R. Jones, and A. McWilliam, (2002). "Domesticating Broadband-What Consumers Really do with Flat Rate, Always-on and Fast Intemet Access," BT Technology Journal, 20:1:103-114.

Alakeson, V. Aldrich, T. Goodman, J. Jorgensen, B. and Miller, P. (2003). Social Responsibility in the Information Society, Final report March 2003. DEESD - Digital Europe: e-business and sustainable development. European Commission 2003. 1-86. pdf document, accessed 02/08/08.

Australian Bureau of Statistics, (2007). Household Use of Information Technology, Australia, 2006-07, 20/12/2007.

B.A.G. 2003, Australia's broadband connectivity, Available From: http://www.noie.gov.au/publications/NOIE/BAG/report/index.htm BBC (2008). EC call for 'universal' Broadband. Available at: http://news.bbc.co.uk/1/hi/technology/7637215.stm. Viewed on: 26/09/08.

BBC (2008). County resists loneliness trend. Available at: http://news.bbc.co.uk/1/hi/england/derbyshire/7738056.stm. Viewed on: March 28, 2009. 
BBC (2009). Plans target Digital Britain push. Available at: http://news.bbc.co.uk/1/hi/technology/7857402.stm. Viewed on: March 28, 2009.

Becker, S.A. (2005). E-Government Usability for Older Adult, Communications of the ACM, 48 (2): 102 - 104.

Bodnar, J., P. Dilworth and S. Iacono (1988). Cross-sectional Analysis of Residential Telephone Subscription in Canada. Information Economics and Policy, 3: 359-378.

Chircu, A. M. (2008). E-Government Evaluation: towards a Multi-Dimensional Framework. Electronic Government, an International Journal, 5, 4: 345-63.

Choudrie, J. and Dwivedi, Y.K. (2006). A Comparative Study to Examine the Socio-Economic Characteristics of Broadband Adopters and Non-Adopters. Electronic Government, an International Journal, 3,3: 272-88.

Choudrie, J. and Dwivedi, Y.K. (2005). THE DEMOGRAPHICS OF BROADBAND RESIDENTIAL CONSUMERS IN A BRITISH LOCAL COMMUNITY: THE LONDON BOROUGH OF HILLINGDON. Journal of Computer Information Systems, Summer.

Choudrie, J, and Y, Dwivedi, (2004). "Analyzing the Factors of Broadband Adoption in the Household," Proceedings of European Conference of Information Systems, Turku Business School, Turku, Finland, June 2004.

Clegg, C., Axtell, C., Damodaran, L., Farbey, B., Hull, R., Lloyd-Jones, R., Nicholls, J., Sell, R. and Tomlinson, C. (1997). Information Technology: a study of performance and the role of Human and organizational Factors, Ergonomics, 40, (9): 851-871.

Crabtree, J. (2003). "Fat Pipes, Connected People-Rethinking Broadband Britain," iSOCIETY Report, London, UK. Crown (Unknown). Modern Councils, Modern Services - Access for all, Office of Deputy Prime Minister, HMSO, Available at:

http://www.odpm.gov.uk/stellent/groups/odpm_localgov/documents/page/odpm_locgov_605195.hcsp.

Digital Inclusion Team (2007). Delivering Social Impact through Information and Communications Technology. Available at: www.ofcom.org.uk. Viewed on: 12/08/08.

Dwivedi, Y.K. and Williams, M. (2008). Demographic Influence on UK Citizens E-Government Adoption. Electronic Government, An International Journal, 5, 3: 261-74.

Farbey, B, Land, F. and Targett, D. (1993). How to Assess your IT investment: A Study of Methods and Practices Management Today. Butterworth-Heinemann, Oxford. 
Firth, L. and Kelly, T., (2001). Broadband briefing paper, ITU, Geneva, Accessed from: www.itu.int/broadband

Goldman, S.L, Nagel, R.N. and Preiss, K. (1995). Agile Competitors and Virtual Organizations, Strategies for Enriching the Customer. Von Nostrand Reinhold, New York.

Hicken, M (2004). To each according to his needs: public libraries and socially excluded people, Health Information and Libraries Journal, 21 (2), pp 45 - 53.

Ironmonger, D. and D.W. Lloyd-Smith, 1992, Projections of households and household populations by household size propensities, Journal of the Australian Population Association 9, 153-171.

Kaplan, D. (2005). e-Inclusion: New challenges and policy recommendations. Available at:

http://ec.europa.eu/information_society/eeurope/2005/doc/all_about/kaplan_report_einclusion_final_version.pdf. Viewed on 12/08/08.

Lee, H, and J, Choudrie, (2002). "Investigating Broadband Technology Deployment in South Korea," Brunel-DTI International Technology Services Mission to South Korea, DISC, Brunel University, Uxbridge, UK.

Lee, H., B. O'Keefe, and K. Yun, (2003). "The Growth of Broadband and Electronic Commerce in South Korea: Contributing Factors," The Information Society, 19: 81-93.

Lee, H., O'Keefe, R.M. and Yun, K. (2003). The Growth of Broadband and Electronic Commerce in South Korea: Contributing Factors. The Information Society 19(1): 81-93.

Leicestershire County Council, (2009). CareOnLine Evaluation Summary. Available at: http://www.leicscareonline.org.uk/index/about_careonline/evaluation.htm\%20. Viewed on: March 28, 2009.

Madden, G. and Simpson, M. (1996). A probit model of household Broadband service subscription intentions: A regional analysis. Information Economics and Policy.8, 3, September: 249-267

McElvey, W. and R. Zavoina (1975). A Statistical Model for the Analysis of Ordinal Level Dependent Variables. Journal of Mathematical Sociology, Summer, 103-109.

Mofleh, S., Wanous, M and Strachan, P. (2009). Understanding national e-government: the role of central government. Electronic Government, an International Journal, 6, 1: 1-18.

Norris, P. (2001). Digital Divide: Civic Engagement, Information Poverty and the Internet in Democratic Societies. New York: Cambridge University Press. 
Ofcom (2008). Communications Market Report. http://www.ofcom.org.uk/research/cm/cmr08/cmr08_1.pdf. Viewed on 27/08/08.

Office of National Statistics (2008). Ageing: $16 \%$ of UK population are aged 65 or over. Source: http://www.statistics.gov.uk/cci/nugget.asp?id=949. Viewed on 23/07/08.

Office of National Statistics (2008). More pensioners than under-16's for first time ever. Source: http://www.statistics.gov.uk/cci/nugget.asp?ID=949. Viewed on 21/08/08.

Rogers, E. M. (1995) Diffusion of Innovations, Free Press, New York

Selwyn, and Craven, (2008). Making Sustainability Real-A Challenge for Regions. Available at: http://www.ukceed.org/downloads/files/81-MakingSustainabilityReal.pdf

Stanton, L.J, (2004). "Factors Influencing the Adoption of Residential Broadband Connections to the Intemet" Proceedings of the $31^{\text {st }}$ Hawaii International Conference on Systems Sciences, Hawaii.

Tapscott, D., Lowy, A., Ticoll, D. and Klymn, N. (1998) Blueprint to the Digital Economy: Creating Wealth in the Era of E-Business. McGraw-Hill, New York, U.S.A.

Rice, C. (1997). Understanding Customers. Oxford: Butterworth- Heinemann.

Venkatesh, V., E. Shih, and N. Stollzoff (2000). A Longitudinal Analysis of Computing at Home, Centre for Research on Information Technology and Organization (CRITO).

Venkatesh, V, and S,A- Brown, (2001). A Longitudinal Investigation of Personal Computers in Homes: Adoption Determinants and Emerging Challenges, MIS Quarterly, 25:1: 71-102

Warschauer, M.(2003). Technology and Social Inclusion: Rethinking the Digital Divide, Cambridge, Mass, MIT Press.

Webster, J. (1998). Desktop Videoconferencing: Experiences of Complete Users, Wary Users and Non-users, MIS Quarterly, 22:3: 257-286. 
TABLE 5 - THE PROBABILITY OF ADOPTING BROADBAND. PROBIT ESTIMATES WITH MARGINAL EFFECTS.

\begin{tabular}{|c|c|c|c|c|c|c|c|c|c|}
\hline & \multicolumn{3}{|c|}{ SPECIFICATION 1: ALL } & \multicolumn{3}{|c|}{ SPECIFICATION 2: AGE $\geq 50$} & \multicolumn{3}{|c|}{ SPECIFICATION 3: AGE $<50$} \\
\hline & 1 & 2 & & 4 & & 6 & \multicolumn{2}{|c|}{$\begin{array}{ll}7 & 8\end{array}$} & \multirow{2}{*}{$\begin{array}{c}9 \\
\text { Marginal } \\
\text { Effects }\end{array}$} \\
\hline & Coeff. & $\mid t$-Stat $\mid$ & $\begin{array}{l}\text { Marginal } \\
\text { Effects }\end{array}$ & Coeff. & $\mid t$-Stat $\mid$ & $\begin{array}{l}\text { Marginal } \\
\text { Effects }\end{array}$ & Coeff. & $\mid t-$ Stat $\mid$ & \\
\hline Constant & 0.771 & 4.04 & & 2.339 & 1.25 & & 0.996 & 3.06 & \\
\hline \multicolumn{10}{|l|}{ PERSONAL } \\
\hline Male & 0.055 & 1.60 & 0.014 & -0.044 & 0.67 & -0.014 & 0.098 & 2.37 & 0.023 \\
\hline Age & -0.003 & 0.35 & -0.001 & -0.050 & 0.84 & -0.016 & -0.014 & 0.73 & -0.003 \\
\hline $\mathrm{Age}^{2} / 100$ & -0.009 & 0.96 & -0.002 & 0.028 & 0.58 & 0.009 & 0.009 & 0.33 & 0.002 \\
\hline \multicolumn{10}{|l|}{ HOUSEHOLD } \\
\hline No of Kids Aged 0-2 & -0.075 & 1.20 & -0.019 & -0.521 & 1.34 & -0.188 & -0.053 & 0.82 & -0.013 \\
\hline No of Kids Aged 3-4 & -0.003 & 0.05 & -0.001 & -0.189 & 0.58 & -0.060 & 0.005 & 0.08 & 0.001 \\
\hline No of Kids Aged 5-11 & -0.003 & 0.13 & -0.001 & -0.077 & 0.67 & -0.024 & -0.001 & 0.02 & 0.000 \\
\hline No of Kids Aged 12-15 & 0.274 & 7.31 & 0.071 & 0.171 & 1.88 & 0.054 & 0.284 & 6.74 & 0.067 \\
\hline No of Kids Aged 16-18 & 0.040 & 0.77 & 0.010 & 0.297 & 2.12 & 0.094 & -0.022 & 0.38 & -0.005 \\
\hline Number of Pensioners & -0.106 & 2.22 & -0.027 & -0.048 & 0.73 & -0.015 & -0.162 & 2.04 & -0.038 \\
\hline \multicolumn{10}{|l|}{ EDUCATION } \\
\hline Degree/Post-Graduate & 0.123 & 1.71 & 0.031 & 0.221 & 1.97 & 0.066 & -0.003 & 0.03 & -0.001 \\
\hline Other Higher Qualification & 0.079 & 1.19 & 0.020 & 0.264 & 2.79 & 0.081 & -0.082 & 0.83 & -0.020 \\
\hline A Levels & 0.127 & 1.69 & 0.031 & 0.234 & 1.85 & 0.069 & 0.009 & 0.09 & 0.002 \\
\hline O levels & 0.016 & 0.22 & 0.004 & 0.060 & 0.54 & 0.019 & -0.084 & 0.83 & -0.021 \\
\hline Other Qualification & 0.047 & 0.52 & 0.012 & 0.035 & 0.26 & 0.011 & -0.029 & 0.23 & -0.007 \\
\hline \multicolumn{10}{|l|}{ LABOUR MARKET } \\
\hline Employee/Self-Employed & 0.115 & 1.08 & 0.031 & 0.304 & 1.40 & 0.101 & 0.067 & 0.53 & 0.016 \\
\hline Retired & 0.124 & 0.81 & 0.030 & 0.269 & 1.12 & 0.078 & & & \\
\hline Out of Labour Force & 0.125 & 1.12 & 0.031 & 0.288 & 1.24 & 0.084 & 0.081 & 0.63 & 0.019 \\
\hline \multicolumn{10}{|l|}{ WEALTH } \\
\hline House Ownership & -0.158 & 3.14 & -0.039 & -0.398 & 3.34 & -0.111 & -0.101 & 1.79 & -0.023 \\
\hline $\begin{array}{l}\text { Household Income } \\
\text { (Labour and Non-Labour) }\end{array}$ & 0.030 & 3.76 & 0.008 & 0.044 & 3.18 & 0.014 & 0.021 & 2.13 & 0.005 \\
\hline \multicolumn{10}{|l|}{ HEALTH } \\
\hline Health Limits Daily & & & & & & 0.044 & & & 0.022 \\
\hline Activities & 0.105 & 1.93 & 0.026 & 0.144 & 1.56 & & 0.097 & 1.40 & \\
\hline \multicolumn{10}{|l|}{ REGION } \\
\hline South East & 0.203 & 3.39 & 0.049 & 0.006 & 0.05 & 0.002 & 0.290 & 4.01 & 0.062 \\
\hline South West & 0.236 & 2.88 & 0.055 & 0.095 & 0.62 & 0.029 & 0.301 & 3.07 & 0.062 \\
\hline East Anglia & 0.263 & 2.32 & 0.060 & 0.051 & 0.24 & 0.016 & 0.339 & 2.51 & 0.068 \\
\hline Midlands & 0.174 & 2.57 & 0.042 & -0.005 & 0.04 & -0.002 & 0.239 & 3.00 & 0.051 \\
\hline North West & 0.354 & 4.28 & 0.079 & 0.416 & 2.59 & 0.114 & 0.326 & 3.36 & 0.066 \\
\hline North East and Yorkshire & 0.132 & 1.90 & 0.033 & -0.033 & 0.24 & -0.010 & 0.196 & 2.39 & 0.043 \\
\hline Wales & -0.017 & 0.30 & -0.004 & -0.193 & 1.76 & -0.064 & 0.053 & 0.77 & 0.012 \\
\hline Scotland & 0.299 & 4.95 & 0.070 & 0.004 & 0.04 & 0.001 & 0.432 & 5.87 & 0.088 \\
\hline \multirow{3}{*}{$\begin{array}{l}\text { Number of Observations } \\
\text { Prob. }>\chi^{2} \\
\text { Predicted Probability of } \\
\text { adopting Broadband }\end{array}$} & \multirow{2}{*}{\multicolumn{3}{|c|}{$\begin{array}{l}7,765 \\
0.000\end{array}$}} & \multirow{2}{*}{\multicolumn{3}{|c|}{$\begin{array}{l}1,987 \\
0.000\end{array}$}} & \multicolumn{3}{|c|}{ "5,775 } \\
\hline & & & & & & & \multirow{2}{*}{\multicolumn{3}{|c|}{$\begin{array}{c}0.000 \\
84.61 \%\end{array}$}} \\
\hline & \multicolumn{3}{|c|}{$82.36 \%$} & \multicolumn{3}{|c|}{$75.29 \%$} & & & \\
\hline
\end{tabular}

